\title{
515 Enhancement in Corrosion Resistance of Laser-Melted Stainless Steel by Passivation Treatment
}

\author{
C.T. Kwok', F.T. Cheng ${ }^{2}$ and H.C. Man ${ }^{3}$ \\ ' Department of Electromechanical Engineering, Faculty of Science and Technology, University of Macau, \\ Taipa, Macau, PR China, fstctk@umac.mo \\ 2 Department of Applied Physics, apaftche@polyu.edu.hk; \\ The Hong Kong Polytechnic University, Hung Hom, Kowloon, Hong Kong, PR China \\ 3 Department of Industrial \& Systems Engineering, mfhcman@inet.polyu.edu.hk, \\ The Hong Kong Polytechnic University, Hung Hom, Kowloon, Hong Kong, PR China
}

\section{Summary}

Martensitic stainless steel AISI 440C was surface melted by a $2.5-\mathrm{kW} \mathrm{CW} \mathrm{Nd:YAG} \mathrm{laser,} \mathrm{followed} \mathrm{by}$ 50 vol-\% nitric acid passivation treatment at $50{ }^{\circ} \mathrm{C}$ for further improvement in corrosion resistance. The corrosion behavior in $3.5 \% \mathrm{NaCl}$ solution of various specimens before and after passivation was studied by potentiodynamic polarization technique. It was found that the pitting corrosion resistance of the laser-melted specimens was significantly improved by $\mathrm{HNO}_{3}$-passivation as evidenced by a shift of the pitting potential in the noble direction, a wider passive range, and a lower passive current density. After passivation treatment, the laser-melted specimens possess higher pitting corrosion resistance than that of as-received and conventionally hardened $440 \mathrm{C}$ which were passivated under the same conditions. The pitting corrosion characteristics of the passivated $440 \mathrm{C}$ specimens were strongly dependent on the microstructures. The enhanced pitting corrosion resistance is due to the combined effect of dissolution or refinement of carbide particles by laser surface melting and removal of carbides inclusions and free iron by passivation treatment.

Keywords : Laser surface melting; Passivation; Pitting corrosion; Martensitic stainless steel

\section{Introduction}

Martensitic stainless steels are widely used in many engineering applications such as steam and water valves, pumps, turbines, compressor components, shafting, cutlery, surgical instruments, bearings and plastics moulds, etc, which demand high hardness, wear and corrosion resistances. Among the martensitic stainless steels, $440 \mathrm{C}$ has the best mechanical properties and the highest chromium and carbon content. The mechanical strength increases but the corrosion resistance decreases as the carbon content in the martensitic stainless steels increases. Thus it is not easy to achieve both high mechanical strength and high corrosion resistance. The corrosion resistance of $440 \mathrm{C}$ is the lowest among this stainless group because of its high carbon content which leads to the precipitation of a large amount of carbide phases.

Laser surface melting (LSM) has been proven to be a promising method for improving the pitting corrosion resistance (1) (5) of martensitic stainless steels by dissolution of large carbides, refinement of the microstructure, and homogenization of chemical compositions. The superficial layer of the steels is modified while the bulk properties of the substrate are preserved, thus providing a possible solution to the conflicting effects due to high carbon content. In a previous paper by the present authors, the pitting corrosion resistance 
of laser-melted 440C was found to increase significantly and depend on the scanning speed which results in different amounts of carbide particles and retained austenite remaining in the melt layer (1). A low scanning speed would result in higher pitting corrosion resistance due to more carbon in solid solution and a higher degree of decarburization. However, it is unavoidable that a small amount of precipitated carbide remains in the laser-melted $440 \mathrm{C}$ and weakens the passive film.

Passivation, according to ASTM A380-99, is "the removal of exogenous iron or iron compounds from the surface of stainless steel by means of a chemical dissolution, most typically by a treatment with an acid solution that will remove the surface contamination, but will not significantly affect the stainless steel itself" (6). In addition, it also describes passivation as "the chemical treatment of stainless steel with a mild oxidant, such as a nitric acid solution, for the purpose of enhancing the spontaneous formation of the protective passive film" (6). Chemical passivation is an inexpensive way for further improvement in pitting corrosion resistance by removing free iron or other anodic contaminants from the surfaces of $440 \mathrm{C}$. These contaminants are potential corrosion sites that result in premature corrosion and ultimately result in deterioration of the component if not removed.

Studies relating to the combined effect of LSM and passivation on the pitting corrosion behavior of martensitic stainless steel $440 \mathrm{C}$ are scarce in the literature. The present work thus aims at improving the pitting corrosion resistance of laser-melted martensitic stainless steel $440 \mathrm{C}$ in $3.5 \% \mathrm{NaCl}$ solution by nitric acid passivation.

\section{Materials and Methods}

The as-received AISI 440C (designated as AR-440C) was in annealed condition and in the form of round bar. The nominal chemical composition in weight $\%$ was : $17 \% \mathrm{Cr}, 0.75 \% \mathrm{Mo}, 1 \% \mathrm{Mn}, 1.1 \% \mathrm{C}, 1 \% \mathrm{Si}$, $0.049 \% \mathrm{P}, 0.03 \% \mathrm{~S}$, balance Fe. Hardened specimen of $440 \mathrm{C}$ (designated as HT-440C) was achieved by conventional heat treatment for comparison with the laser-melted specimens. Specimens were preheated to, and kept at, $850^{\circ} \mathrm{C}$ for 45 minutes and then heat-treated through the austenitizing temperature $\left(1060^{\circ} \mathrm{C}\right)$ for 30 minutes, followed by quenching in liquid nitrogen. Tempering was achieved by keeping the specimens at $250^{\circ} \mathrm{C}$ for 210 minutes followed by air cooling.

The specimens for polarization studies were machined to discs $12.7 \mathrm{~mm}$ in diameter and $3.2 \mathrm{~mm}$ thick. The surface of the specimens for LSM was sandblasted in order to reduce the reflectivity to the laser beam. Prior to passivation procedures, the surface of as-received, hardened and laser-melted specimens was mechanically polished with $1-\mu \mathrm{m}$ diamond paste in order to keep the surface roughness consistent. The specimens were then passivated in nitric acid, cleaned, degreased and dried before the polarization test.

LSM was carried out using a $2.5-\mathrm{kW}$ CW Nd:YAG laser. The laser beam was focused onto the specimen by a BK-7 glass lens with focal length of $100 \mathrm{~mm}$. Laser power $(P)$ of $0.8 \mathrm{~kW}\left(2.8 \mathrm{~kW} / \mathrm{cm}^{2}\right)$ at workpiece with a laser spot size of $6 \mathrm{~mm}$ in diameter and beam scanning speed $(v)$ of $25 \mathrm{~mm} / \mathrm{s}$ were used. Argon flowing at $15 \mathrm{l} / \mathrm{min}$ was used as shielding gas. The designation of the laser-melted specimen is P08-440C-25. The melt surface was achieved by overlapping of successive melt tracks at $50 \%$ track width interval.

The passivation procedures were based on ASTM Standard A380-99(6). The specimens were immersed 
in ethanol in an ultrasonic cleaner to remove organic or metallic residues. The specimens were then placed into 50 vol- $\%$ nitric acid at constant temperature $\left(50 \pm 1{ }^{\circ} \mathrm{C}\right)$ for 30 minutes. After immersion in the passivation bath, the specimens were cleaned by running tap water and then placed into a copper sulfate solution for verification. Absence of pink spots indicated that no residual iron was present on the surface of all the specimens.

Polarization studies were performed in $3.5 \% \mathrm{NaCl}$ solution to investigate the electrochemical corrosion behavior of the laser-melted, the as-received and the hardened specimens. Cyclic potentiodynamic polarization scans were carried out using an EG\&G PARC 273 corrosion system according to ASTM Standard G61-94 (7). The $\mathrm{NaCl}$ solution was maintained at $23 \pm 1^{\circ} \mathrm{C}$ open to air. A constant scan rate of $5 \mathrm{mV}$ $\mathrm{s}^{-1}$ was used. All potentials were measured with respect to a saturated calomel electrode (SCE, $0.244 \mathrm{~V}$ versus SHE at $25^{\circ} \mathrm{C}$ ) as the reference electrode. Two parallel graphite rods served as the counter electrode for current measurement. Potential scans started after an initially delay of 30 minutes for the specimen to reach a steady state. The scan was reversed when a current density of $5 \mathrm{~mA} / \mathrm{cm}^{2}$ was reached.

\section{Results and discussion}

The cross-sectional appearance and microstructure of the laser-melted specimen P08-440-25 is shown in Fig. 1. The surface layer of P08-440-25 is free of cracks and pores. The melt depth is $0.29 \mathrm{~mm}$. In the melted zone ( $\mathrm{MZ}$ ), the $\mathrm{M}_{23} \mathrm{C}_{6}$ carbide was dissociated to form a homogeneous structure. Primary austenitic dendrites (bright in contrast) and interdendritic regions which consist of martensite and secondary $\mathrm{M}_{23} \mathrm{C}_{6}$ and $\mathrm{M}_{7} \mathrm{C}_{3}$ carbides (darker in contrast) are observed in Fig. 1(b). Beneath the MZ, a heat-affected zone (HAZ) with a depth of about $0.21 \mathrm{~mm}$ was observed. The HAZ corresponded to complete austenitization of the steel together with dissolution of $\mathrm{M}_{23} \mathrm{C}_{6}$ carbide and a final martensite transformation upon rapid cooling, with some undissolved carbide particles.

Potentiodynamic polarization curves of the laser-melted specimens (for MZ and HAZ), as-received and hardened specimens before and after passivation treatment in $3.5 \% \mathrm{NaCl}$ solution (open to air) at $23{ }^{\circ} \mathrm{C}$ are shown in Figs. 2 and 3. The corrosion parameters are summarized in Table 1.

Prior to passivation treatment, AR-440C did not passivate, HAZ of P08-440C-25 and HT-440C had a low pitting potential, both being attributable to the large amount of carbide particles present in the ferritic or martensitic matrix, respectively (Table 1). The carbide particles had very high chromium content so that the matrix was depleted of chromium, especially in the region next to the carbide particles. The boundaries between the carbide particles and the metal matrix then acted as the nucleation and anodic sites for pitting corrosion in a chloride medium ${ }^{(9)}$. For P08-440C-25, the pitting corrosion potential became higher and the passive current density was lower than those of AR-440C, HT-440C and the HAZ of P08-440C-25 as shown in Fig. 3 and Table 1. In the present study, the scanning speed for LSM was $25 \mathrm{~mm} / \mathrm{s}$, resulting in a constant proportion of retained austenite ${ }^{(1,8)}$. LSM of $440 \mathrm{C}$ is capable of improving the pitting corrosion resistance by reducing the amount and the size of the $\mathrm{M}_{23} \mathrm{C}_{6}$ carbides and increasing the amount of retained austenite ${ }^{(8)}$.

After the passivation treatment, the pitting corrosion resistance of the laser-melted specimens (for $\mathrm{MZ}$ and $\mathrm{HAZ}$ ), as-received and hardened specimens was significantly improved as evidenced by a shift of the pitting potential in the noble direction, a wider passive range, and a lower passive current density (in the 
order $\mu \mathrm{A} / \mathrm{cm}^{2}$ ) (Table 1). Under the same passivation conditions, MZ of P08-440C-25 possess higher pitting corrosion resistance than that of conventionally hardened and as-received $440 \mathrm{C}$, and the HAZ of P08-440C-25. The pitting corrosion characteristics of the passivated 440C were strongly dependent on the microstructures prior to passivation treatment. The enhanced pitting corrosion resistance of laser-melted $440 \mathrm{C}$ after passivation is due to the combined effect of dissolution or refinement of carbide particles by LSM and removal of carbides inclusions and free iron by passivation treatment. The ranking of pitting corrosion resistance of the laser-melted $440 \mathrm{C}$ before and after passivation is consistent. In descending order, the ranking is : P08-440C-25 (MZ) $>$ HT -440C $>$ P08-440C-25 (HAZ) $>$ AR-440C.

P08-440C-25 had a pitting potential of $260 \mathrm{mV}$ before passivation, and increased to $900 \mathrm{mV}$ after passivation. At such a low scanning speed $(25 \mathrm{~mm} / \mathrm{s})$, more carbides dissolved into the matrix due to a longer laser interaction time and the remaining carbides were then removed by passivation. Vayer and his coworkers reported that chromium carbide inclusions are present on the surface of the martensitic stainless steel and pitting corrosion yields elimination of these inclusions ${ }^{(10)}$. The pitting potential of martensitic stainless steels (X20Cr13, X30Cr13 and X40Cr14) after $\mathrm{HNO}_{3}$-passivation in Hexanios solution (containing 43 ppm Cl, $\mathrm{pH}$ -7.3) was more noble than air-passivated specimens (11). The $\mathrm{HNO}_{3}$-passivated film was enriched in oxidized chromium and hydroxide. Oxidized chromium and oxidized iron were uniformly distributed all over the passive layer. The beneficial effect of $\mathrm{HNO}_{3}$-passivation for pitting corrosion resistance of laser-melted 440C is in agreement with the work by Vayer et al (11).

On the other hand, the repassivation capability of the laser-melted specimen with and without passivation is poor as indicated by the low protection potential (below the corrosion potential). This indicates that the amount of $\mathrm{Cr}$ present in solid solution in the treated layer was still not sufficiently high to effect rapid repassivation.

\section{Conclusions}

(1) LSM of $440 \mathrm{C}$ results in an increase the pitting corrosion resistance, as demonstrated by a higher pitting potential and a lower the passive current density (of the order of $\mu \mathrm{A} / \mathrm{cm}^{2}$ ) compared with the as-received and conventional hardened $440 \mathrm{C}$.

(2) After passivation treatment, the pitting corrosion resistance of all the specimens was improved. The ranking of pitting corrosion resistance both before and after passivation is the same. In descending order, the ranking is : P08-440C-25 (MZ) > HT-440C > P08-440C-25 (HAZ) >AR-440C.

(3) After passivation treatment, the pitting potential of the melted zone of laser-melted 440C was increased from $260 \mathrm{mV}$ to $900 \mathrm{mV}$ (SCE), which was much higher than that of the annealed $440 \mathrm{C}(287 \mathrm{mV}$ ) and the heat-affected zone of laser-melted $440 \mathrm{C}(430 \mathrm{mV})$ passivated under the same conditions.

(4) The enhanced pitting corrosion resistance of laser-melted specimens with passivation treatment is due to the combined effect of dissolution or refinement of carbide particles by LSM and removal of chromium carbide inclusions and free iron by $\mathrm{HNO}_{3}$-passivation.

\section{Acknowledgements}

The authors wish to acknowledge the support from the infrastructure of the University of Macau and 
The authors wish to acknowledge the support from the infrastructure of the University of Macau and the Hong Kong Polytechnic University.

\section{References}

(1) C.T. Kwok, K.H. Lo, F.T. Cheng and H.C. Man, Surface and Coatings Technol., 166 (2003) 221-230.

(2) C.T. Kwok, H.C. Man, F.T. Cheng, Surface \& Coat. Technol., 126 (2000) 238-255.

(3) A. Conde, R. Colaco, R. Vilar, J. de Damborenea, Materials \& Design, 21 (2000) 441-445.

(4) M.L. Escudero, J.M. Bello, Mater. Sci. Eng. A, 158 (1992) 227-233.

(5) S. Song, Z. Tang, Mater. Chem. Phy. 28 (1991) 281-289.

(6) ASTM Standard A380-99, Standard Method for Cleaning, Descaling, and Passivation of Stainless Steel Parts, Equipments, and Systems, in Annual Book of ASTM Standards, ASTM, Philadelphia, 2000.

(7) ASTM Standard G61-86, Standard Method for Conducting Cyclic Potentiodynamic Polarization Measurements for Localized Corrosion Susceptibility of Iron-, Nickel-, or Cobalt-Based Alloys, in Annual Book of ASTM Standards, Vol. 03.02, ASTM, Philadelphia, 1992.

(8) R. Colaco, R. Vilar, J. Mater. Sci. Lett. 17 (1998) 563-567.

(9) B. Baroux, 'Furthur Insights on the Pitting Corrosion of Stainless Steels, in Corrosion Mechanism in Theory and Practice, P. Marcus \& J. Oudar (Ed.), NY, p. 273 (1995).

(10)I. Reynaud, M. Vayer, J.P. Kauffmann and R. Erre, Microsc. Microanal. Microstruct. 8 (1997) 175.

(11) M. Vayer, I Reynaud, R. Erre, J. Mater. Sci., 35 (2000) 2581-2587.

\begin{tabular}{lcc}
\hline Specimens & Corrosion potential $(\mathrm{mV})$ SCE & Pitting potential (mV) SCE \\
\hline AR-440C & -482 & active \\
AR-440C (passivated) & -270 & 287 \\
HT-440C & -280 & -150 \\
HT-440C (passivated) & -161 & 840 \\
P08-440C-25 (MZ) & -206 & 260 \\
P08-440C-25 (MZ, passivated) & -277 & 900 \\
P08-440C-25 (HAZ) & -287 & -163 \\
P08-440C-25 (HAZ, passivated) & -206 & 430 \\
\hline
\end{tabular}

Table 1. Corrosion parameters of as-received, hardened and laser-melted 440C (for MZ and HAZ) before and after passivation in $3.5 \% \mathrm{NaCl}$ solution at $23^{\circ} \mathrm{C}$.
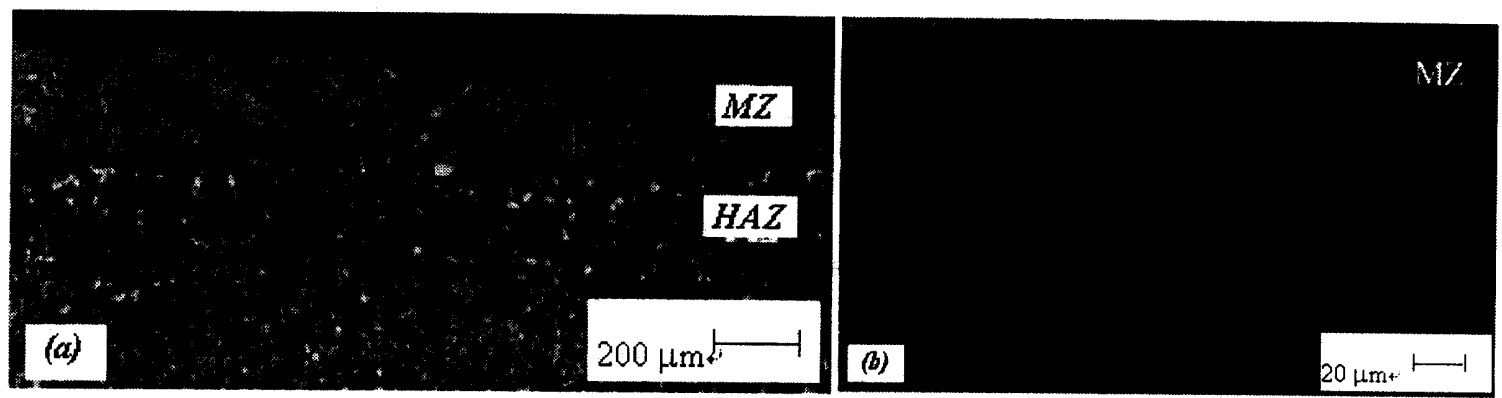

Fig. 1. (a) Cross-sectional view \& (b) microstructure of laser-melted specimen P08-440C-25. 


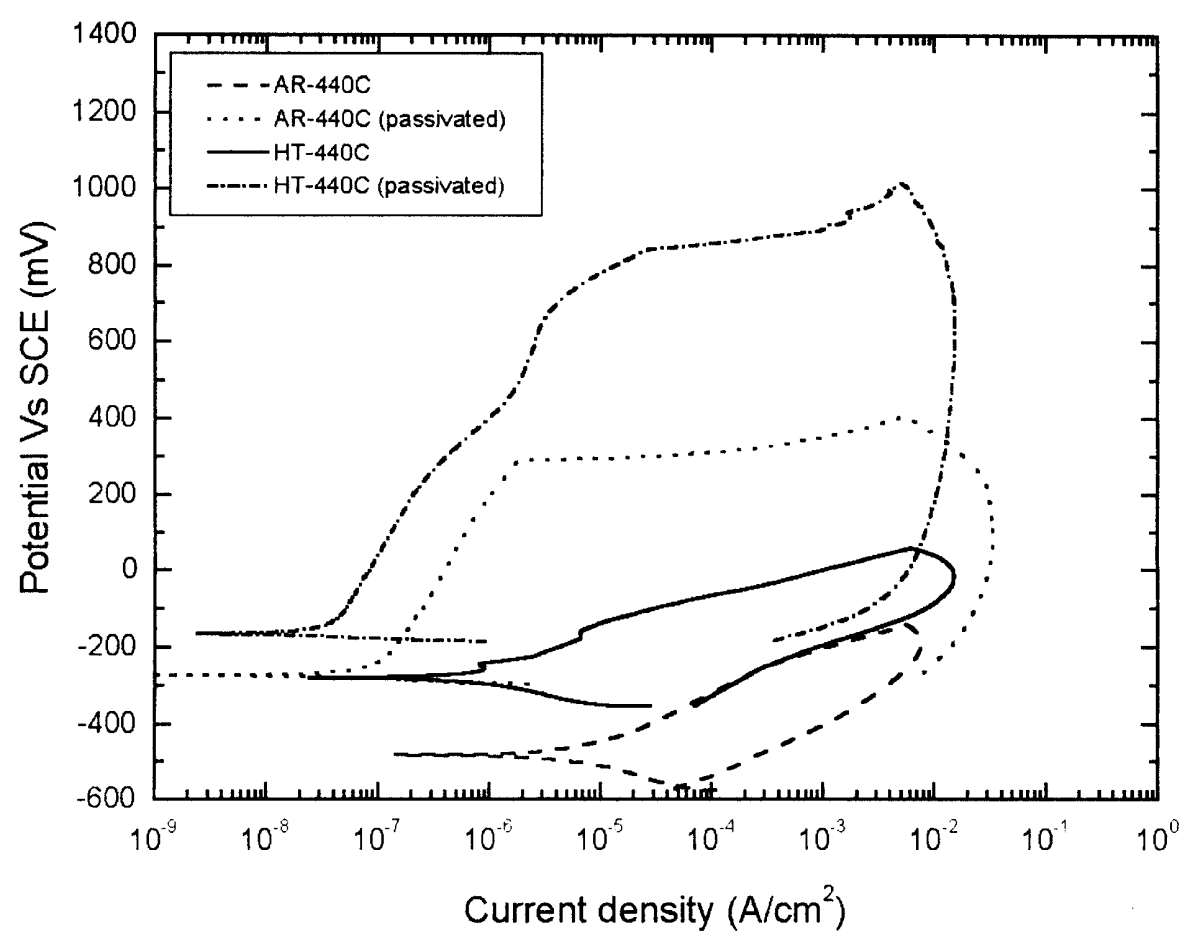

Fig. 2. Potentiodynamic polarization curves of as-received and hardened $440 \mathrm{C}$ before and after passivation in $3.5 \% \mathrm{NaCl}$ at $23{ }^{\circ} \mathrm{C}$.

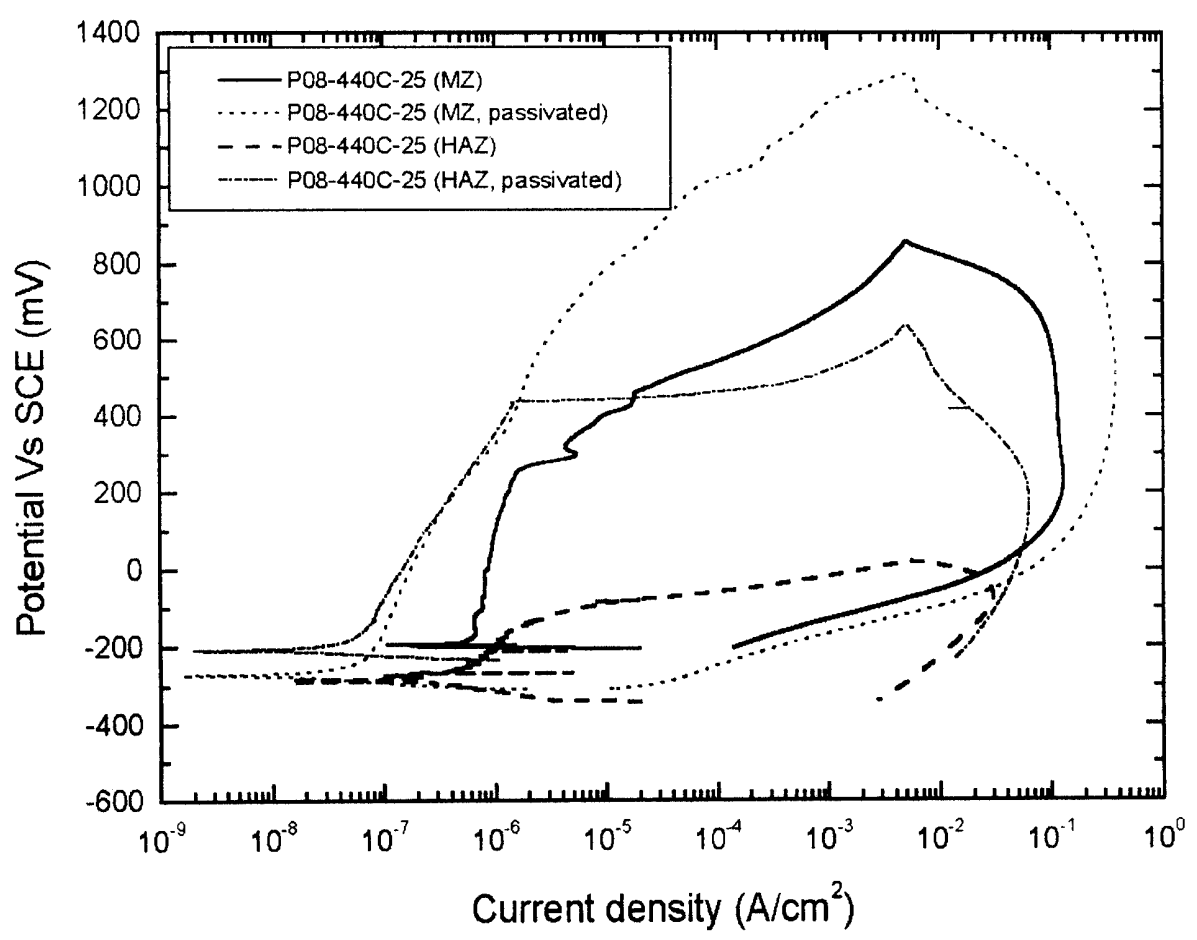

Fig. 3. Potentiodynamic polarization curves of laser-melted $440 \mathrm{C}$ ( $\mathrm{MZ}$ and $\mathrm{HAZ}$ ) before and after passivation in $3.5 \% \mathrm{NaCl}$ at $23{ }^{\circ} \mathrm{C}$. 